\title{
Variations in number of births and perinatal mortality by day of week in England and Wales
}

\section{Summary and conclusions}

Analysis of the births that occurred in England and Wales during 1970-6 showed that they followed a seven-day cycle, being concentrated from Tuesdays to Fridays and least numerous on Sundays. This pattern became increasingly pronounced during the period examined. Relatively few births occurred on bank holidays, especially Christmas Day and Boxing Day. In general perinatal mortality was higher among babies born at weekends than among those born on weekdays.

It is likely that the pattern seen in the numbers of births is associated to a large extent with elective intervention. It is not possible to draw any conclusions about the pattern seen in perinatal mortality as so far the analysis has been confined to crude rates.

\section{Introduction}

The child of Sunday and Christmas day

Is good and wise and fair and gay.

According to the well-known nursery rhyme, of which the lines above are a variant, the day of the week of a person's birth influences their character and fortune in life. A recent newspaper cartoon, depicting a maternity unit with a notice "No deliveries at weekends," reflected a popular suspicion that modern obstetric practices act to concentrate births on weekdays. This paper investigates this idea in England and Wales and examines possible associations with perinatal mortality among infants born on each day of the week.

\section{Material and methods}

Counts were produced of the numbers of live births and stillbirths occurring on each day during 1970-6 according to the type of institution in which the birth took place. In order to do this, the Office of Population Censuses and Surveys (OPCS) had to derive computer files of births occurring in each of these years. As most of their published tables give births and deaths registered in a given year, the numbers and rates given here will differ slightly from published data. The daily birth counts were examined graphically using the microfilm plotter at the University of London computer centre. Files of records of infant deaths provided by the OPCS were sorted to provide counts of perinatal deaths for infants born on each day of 1970-6 (except December 1976, for which complete data on death occurrences are not yet available).

Department of Medical Statistics and Epidemiology, London School of Hygiene and Tropical Medicine, and Medical Statistics Division, Office of Population Censuses and Surveys, London

ALISON MACFARLANE, BA, DIPSTAT, statistician (present address: National Perinatal Epidemiology Unit, Research Institute, Churchill Hospital, Oxford OX3 7LJ)

\section{Results}

BIRTHS

Figure 1 shows the total number of live births and stillbirths on each day of 1970; each day's total was plotted individually and the points joined consecutively. A pronounced regular cycle of births is apparent. The cycle repeats itself every seven days, the number of births being minimum on Sundays and reaching a maximum between Tuesdays and Fridays. The most notable disturbance of this pattern was at Christmas. In 1970 Christmas Day was a Friday, and fewer births occurred that day than on any other Friday of the year. On Boxing Day (Saturday) the number of births reached its minimum for the whole year. The number of births in the week before Christmas week was distinctly higher than the numbers on the corresponding days in the three preceding weeks.

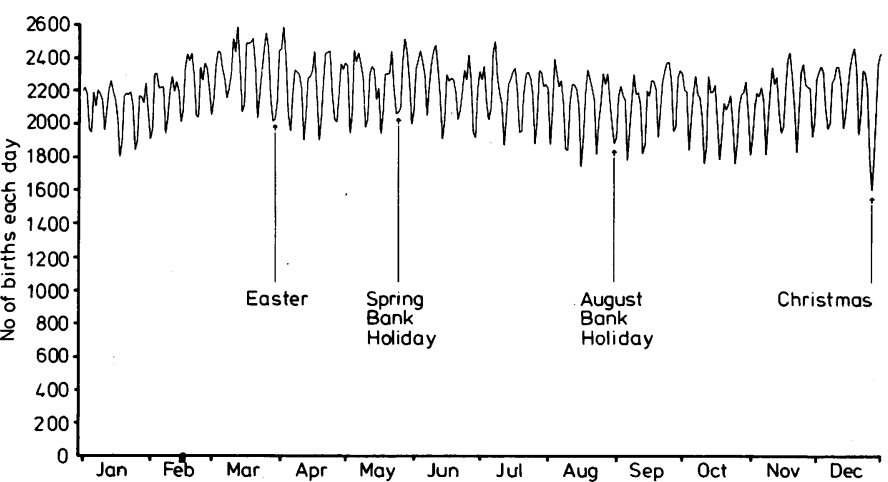

FIG 1-Total number of births (including stillbirths) in England and Wales on each day of 1970 .

A distinct, if less dramatic, deviation from the usual weekly pattern Accurred at Easter. There were as many births on Good Friday as on the other Fridays of February and March, but the number on Easter Saturday was low compared with the other Saturdays. The numbers of births on Easter Monday and the Tuesday of Easter week were also comparatively low. On both the Spring (25 May) and August (31 August) Bank Holiday Mondays fewer births occurred than on the other Mondays of the relevant seasons, and the numbers of births on the Tuesdays that followed were also relatively low.

By 1976 the weekly cycle had become more exaggerated (see fig 2).

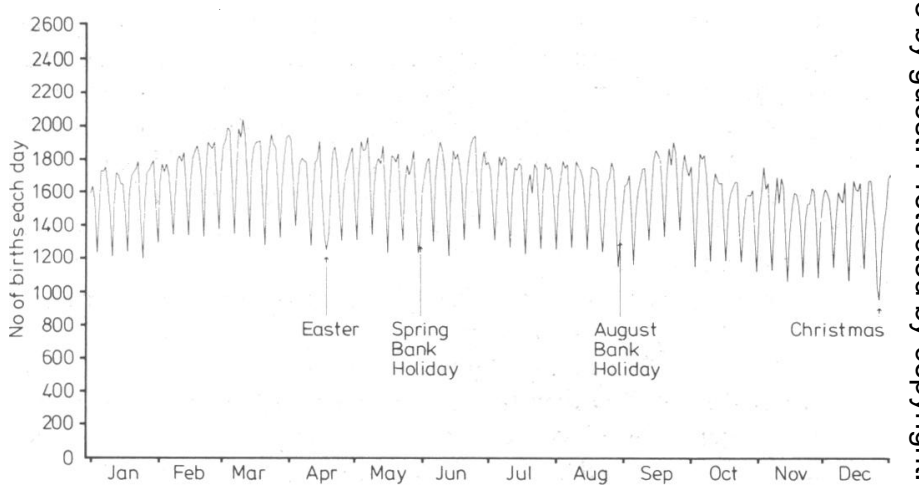

FIG 2-Total number of births (including stillbirths) in England and Wales on each day of 1976. 
The absolute number of births had dropped considerably due to the declining birth rate. Christmas appears to have had a less exaggerated effect, but this may have been because it fell at a weekend, Christmas Day being a Saturday. As in 1970 the numbers of births on bank holiday Mondays were relatively low, but this deficit was no longer apparent on the Tuesdays following them.

Table I summarises the data for all the years and shows the ratio of the average number of births on each day of the week to the average number of births on each day of the year. There was a steady decline in the relative frequency of births on Saturdays and Sundays and a corresponding increase in the proportion of births on weekdays.

The results given in table I were calculated separately for each type of place of delivery (see Appendix 1*). Births in NHS hospitals showed a similar pattern to that in table I. As these births, which include those to the small proportion of private patients in NHS hospitals, accounted for $73^{\circ} \%$ of the total occurring in 1970 , rising to $88 \%$ of all those in 1976, they are bound to dominate the pattern in table I. The pattern for non-NHS hospitals (which accounted for under $2 \%$ of the births), while showing the same features as that for all births, was much more pronounced: the ratio of births on Sundays to the daily average was 0.84 in 1970 , falling to 0.69 in 1976 .

Births certified as having occurred at home accounted for $13 \%$ of the births in 1970 but only $2.5 \%$ of those in 1976 . Ratios for each day of the week varied much less than for hospital births, but a distinctive cycle was still apparent, with the ratio of births at weekends to the average daily birth rate remaining fairly stable at 0.90 for Sundays and 0.95 for Saturdays throughout the period, while more births occurred at home on Tuesdays and Wednesdays than on the other weekdays. For births in general practitioner maternity units, which accounted for $12 \%$ of the total in 1970 and had fallen to $8 \%$ by 1976 , the weekly pattern was midway between that for births in NHS hospitals and that for births at home.

TABLE I-Ratio of average number of births on each day of the week to average number of births per day over whole year in England and Wales during 1970-6

\begin{tabular}{|c|c|c|c|c|c|c|c|}
\hline & 1970 & 1971 & 1972 & 1973 & 1974 & 1975 & $1976^{*}$ \\
\hline $\begin{array}{l}\text { Sunday } \\
\text { Monday . . } \\
\text { Tuesday _. } \\
\text { Wednesday } \\
\text { Thursday .. } \\
\text { Friday } \quad . \\
\text { Saturday . . }\end{array}$ & $\begin{array}{l}0.88 \\
0.92 \\
1.03 \\
1.06 \\
1.06 \\
1.05 \\
1.00\end{array}$ & $\begin{array}{l}0.87 \\
0.92 \\
1.04 \\
1.06 \\
1.06 \\
1.07 \\
0.99\end{array}$ & $\begin{array}{l}0.84 \\
0.93 \\
1.04 \\
1.07 \\
1.06 \\
1.08 \\
0.98\end{array}$ & $\begin{array}{l}0.81 \\
0.94 \\
1.04 \\
1.07 \\
1.08 \\
1.08 \\
0.98\end{array}$ & $\begin{array}{l}0.79 \\
0.96 \\
1.06 \\
1.08 \\
1.08 \\
1.09 \\
0.95\end{array}$ & $\begin{array}{l}0.78 \\
0.96 \\
1.07 \\
1.09 \\
1.08 \\
1.09 \\
0.93\end{array}$ & $\begin{array}{l}0.77 \\
0.97 \\
1.07 \\
1.08 \\
1.09 \\
1.08 \\
0.93\end{array}$ \\
\hline $\begin{array}{l}\text { Total No } \\
\text { of births }\end{array}$ & 795503 & 792493 & 733916 & 683650 & 646842 & 609787 & 545012 \\
\hline
\end{tabular}

*Based on January to November only.

\section{PERINATAL MORTALITY}

Perinatal mortality rates-that is, the ratio of stillbirths and deaths in the first week of life to all births-for infants born on each day of the week during 1970-6 are shown in table II. Within each year there was a pronounced weekly cycle, mortality being higher at the weekend than in the week. The results of a likelihood ratio test of a uniform

*Appendix 1 may be obtained from the author.

TABLE II-Perinatal mortality (perinatal deaths/1000 total births) in England and Wales, 1970-6, according to day of week of birth

\begin{tabular}{|c|c|c|c|c|c|c|c|}
\hline & 1970 & 1971 & 1972 & 1973 & 1974 & 1975 & $1976^{*}$ \\
\hline $\begin{array}{ll}\text { Sunday } & \ldots \\
\text { Monday } & \ldots \\
\text { Tuesday } & \ldots \\
\text { Wednesday } & \ldots \\
\text { Thursday } & \ldots \\
\text { Friday } & \ldots \\
\text { Saturday } & \ldots\end{array}$ & $\begin{array}{l}25 \cdot 50 \\
23 \cdot 68 \\
22 \cdot 82 \\
22 \cdot 84 \\
23 \cdot 11 \\
22 \cdot 36 \\
24 \cdot 00\end{array}$ & $\begin{array}{l}23.63 \\
22.59 \\
21.33 \\
22.27 \\
21.79 \\
21.65 \\
22.77\end{array}$ & $\begin{array}{l}23.62 \\
22 \cdot 02 \\
20.57 \\
21.67 \\
21.33 \\
20 \cdot 68 \\
22 \cdot 87\end{array}$ & $\begin{array}{l}22 \cdot 88 \\
20.47 \\
20.93 \\
19.93 \\
20.50 \\
21 \cdot 29 \\
21 \cdot 31\end{array}$ & $\begin{array}{l}21 \cdot 91 \\
19 \cdot 92 \\
19 \cdot 51 \\
19 \cdot 05 \\
19 \cdot 55 \\
20 \cdot 81 \\
22 \cdot 29\end{array}$ & $\begin{array}{l}21.59 \\
18.33 \\
18.03 \\
18.80 \\
18.99 \\
18.40 \\
21 \cdot 68\end{array}$ & $\begin{array}{l}20 \cdot 01 \\
15 \cdot 83 \\
17.64 \\
16.97 \\
17.40 \\
16.99 \\
19 \cdot 13\end{array}$ \\
\hline All days & $23 \cdot 42$ & $22 \cdot 24$ & $21 \cdot 76$ & 20.98 & $20 \cdot 35$ & $19 \cdot 28$ & $17 \cdot 61$ \\
\hline 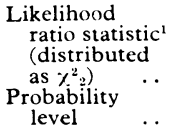 & 0.0001 & 9.09 & 0.0002 & $13 \cdot 32$ & $<0.000001$ & $<0.000001$ & 13.54 \\
\hline
\end{tabular}

*Based on January to November only. distribution against a simple harmonic trend ${ }^{1}$ showed that if perinatal mortality had been the same throughout the week these results would have been unlikely to have occurred by chance. In 1970-3 mortality was highest on Sunday, and although the second highest mortality was on Saturday, it did not greatly exceed that for Monday (except in 1973, when mortality on Friday was closest to that on Saturday). In 1974 and 1975 mortality on Saturday was marginally higher than that on Sunday, and both rates were considerably higher than those for the rest of the week. In 1976 a similar pattern occurred, but mortality on Sunday was marginally higher than that on Saturday.

Stillbirths and early neonatal deaths (deaths in the first week of life) were then analysed separately (appendix 1). The stillbirth rates, except those for 1973, showed evidence of a harmonic trend and were higher at the weekends than on weekdays. While during 1970-2 the rates were slightly higher on Sundays than Saturdays, during 1974-6 the reverse was the case. Early neonatal death rates also showed a cyclic trend, which changed over the period. During 1970-2 Sunday and Monday had similarly raised early neonatal death rates compared with the rest of the week. From 1973 onwards, however, early neonatal mortality was greatest at weekends and Sunday began to stand out increasingly as the day on which the rate was highest.

The early neonatal death rates were further subdivided into deaths in the first 24 hours of life and deaths in the remainder of the first week. In general rates of death in the first 24 hours varied more throughout the week than did those for the remaining early neonatal deaths. In every year except 1971 a pronounced cyclic trend in firstday deaths was evident, and, except in 1975, Sunday stood out as the day with the highest mortality. In 1971 and 1973-5 there was no evidence of a cyclic trend in deaths at age 1-6 days, but there was such a trend in 1970,1972, and 1976. In 1972 and 1976 mortality at age 1-6 days was highest among children born at the weekend.

\section{Discussion}

\section{DAY OF BIRTH}

The variation in numbers of births according to the day of the week is not unique to England and Wales: similar distributions have been reported from Australia and the United States. An analysis of live births occurring in 1968 and 1969 to mothers in New South Wales ${ }^{2}$ showed that the number of births on Sundays was only 0.85 of the daily average for the year and the numbers on public holidays were fewer than the average for the day of the week on which they occurred. In Wisconsin a study of births in $1972^{3}$ showed that the number of births on Sundays was 0.86 of the daily average.

It might be suggested that these patterns in births by day of the week could be due to physiological variations in the timing of the onset of spontaneous labour, or that possible variations by day of the week in the risk of conception might carry through to the spontaneous termination of gestation, but there is no hard information to support this. It seems more likely (particularly in view of the disruption of the pattern seen at bank holidays) that the variation is a reflection of obstetric practice. The OPCS birth record does not contain details of obstetric intervention, so the extent to which developments in obstetric practice might have influenced the pattern of deliveries cannot be examined. For example, accelerating labour of spontaneous onset became common practice over the years studied and this will have resulted in a greater proportion of births having occurred on the day on which labour commenced.

A more important influence is likely to have been an increasingly frequent resort to elective delivery achieved by either induction of labour or elective caesarean section. Both of these procedures have generally become more common, although their incidence varies widely. ${ }^{4}$ An analysis of a sample of the births during $1963-7^{5}$ suggested that the ratio of births on Sundays to the daily average for each year stayed at around 0.92 , in contrast to the decrease from 0.88 in 1970 to 0.77 in 1976 . The percentage of elective deliveries was fairly low in the mid-1960s $-3.4 \%$ of all deliveries were by caesarean section and $12.7 \%$ followed induction in $1966^{6}$ (see Appendix 2 for how these percentages were estimated). By 1974 these percentages had risen to $5.3 \%$ by caesarean section and $38.9 \%$ after induction. ${ }^{6}$ 
The percentage of inductions then began to fall slightly. In 1975, the most recent year for which the data from the Hospital InPatient Enquiry have been analysed, an estimated $35.0^{\circ}{ }_{0}$ of deliveries followed induction, whereas the incidence of caesarean section rose to an estimated $5 \cdot 7^{\circ}$.

Delivery in hospital became much more common during 19706. As this is where elective intervention is most likely to occur, it is appropriate to compare variation by day of the week in births in hospital with those in other places of delivery. Elective delivery is more common in private patients ${ }^{7}$ and thus, on balance, is probably more common in non-NHS than NHS hospitals. This would increase the possibility of avoiding weekend deliveries in non-NHS hospitals and may explain why weekend deliveries there are relatively less common. In addition, the variation according to the day of the week of births in general practitioner maternity units is less than that in hospitals; this may be linked with the lower proportion of elective deliveries in these units $\left(1.0^{\circ}{ }_{0}\right.$ by caesarean section and $16.4^{\circ}{ }_{0}$ after induction in 1975). Elective delivery is probably rarely used for births at home, but there is nevertheless a slight deficit of births at home on Saturdays and Sundays. There are traditional nonmedical methods of starting labour (hot baths, castor oil, gin, physical exercise, etc), although it is not known how effective these measures are nor whether mothers are less likely to resort to them at the weekend. Alternatively the weekend deficit may be a selection effect resulting from a greater likelihood of a woman booked for home confinement being transferred to hospital at the weekend. As these numbers would be small compared with hospital births, they would not be expected to increase perceptibly the numbers of births in hospital at weekends.

\section{PERINATAL DEATHS}

The annual perinatal mortality rates, shown in table II, dropped noticeably from 1970 to 1976 , but both the stillbirth and the early neonatal death rates increasingly tended to be raised at weekends (table III). A study of mortality in infants of very low birth weight in South-east London ${ }^{8}$ also found a raised mortality at weekends. There are several possible explanations for this, which are not necessarily mutually exclusive. One interpretation is that the higher mortality is associated with the lower level of staffing that is likely to occur at weekends. Another possibility is that elective intervention may act to concentrate not only certain categories of high-risk births but also relatively large numbers of low-risk births at term on to weekdays. Thus as the relative frequencies of births on Saturdays and Sundays decreased the ratios of perinatal death rates on those days to the yearly rate became higher, while the ratio for perinatal deaths on Mondays fell as the relative frequency of births increased.

In the South-east London study ${ }^{8}$ spontaneous preterm births,

TABLE III-Ratios of births and perinatal mortality on Saturdays, Sundays, and Mondays to average values for respective years

\begin{tabular}{|c|c|c|c|c|c|c|c|c|c|}
\hline & & & 1970 & 1971 & 1972 & 1973 & 1974 & 1975 & 1976 \\
\hline \multicolumn{10}{|c|}{ Saturday } \\
\hline \multirow{5}{*}{\multicolumn{2}{|c|}{$\begin{array}{c}\text { Births... } \\
\text { Perinatal mortality } \\
\text { Stillbirth rate } \\
\text { Early neonatal } \\
\text { mortality }\end{array}$}} & . & 1.00 & 0.99 & 0.98 & 0.98 & 0.95 & 0.93 & 0.93 \\
\hline & & $\ldots$ & 1.02 & $1 \cdot 02$ & 1.05 & 1.02 & $1 \cdot 10$ & $1 \cdot 12$ & 1.09 \\
\hline & & $\cdots$ & 1.03 & 1.04 & 1.07 & $1 \cdot 01$ & $1 \cdot 11$ & $1 \cdot 18$ & $1 \cdot 11$ \\
\hline & & . & $1 \cdot 02$ & $1 \cdot 01$ & 1.03 & 1.03 & $1 \cdot 08$ & $1 \cdot 07$ & 1.06 \\
\hline & & \multicolumn{8}{|c|}{ Sunday } \\
\hline \multirow{4}{*}{\multicolumn{2}{|c|}{$\begin{array}{c}\text { Perinatal mortality } \\
\text { Stillbirth rate } \\
\text { Early neonatal } \\
\text { mortality }\end{array}$}} & $\cdots$ & $\begin{array}{l}0.88 \\
1.09\end{array}$ & $\begin{array}{l}0.87 \\
1.06\end{array}$ & $\begin{array}{l}0.84 \\
1.09\end{array}$ & $\begin{array}{l}0.81 \\
1.09\end{array}$ & $\begin{array}{l}0.79 \\
1.08\end{array}$ & $\begin{array}{l}0 \cdot 78 \\
1.12\end{array}$ & $\begin{array}{l}0 \cdot 77 \\
1 \cdot 14\end{array}$ \\
\hline & & $\because$ & $\begin{array}{l}1 \cdot 09 \\
1 \cdot 10\end{array}$ & $\begin{array}{l}1.06 \\
1.08\end{array}$ & $\begin{array}{l}1.09 \\
1.07\end{array}$ & $\begin{array}{l}1.09 \\
1.08\end{array}$ & $\begin{array}{l}1.08 \\
1.04\end{array}$ & $\begin{array}{l}1 \cdot 12 \\
1 \cdot 10\end{array}$ & $\begin{array}{l}1.14 \\
1.07\end{array}$ \\
\hline & & . & 1.08 & $1 \cdot 04$ & $1 \cdot 10$ & $1 \cdot 10$ & $1 \cdot 12$ & $1 \cdot 14$ & $1 \cdot 21$ \\
\hline & & \multicolumn{8}{|c|}{ Monday } \\
\hline Births... $\ldots$ & & . & 0.92 & 0.92 & 0.93 & 0.94 & 0.96 & 0.96 & 0.97 \\
\hline \multirow{3}{*}{$\begin{array}{c}\text { Perinatal mortality } \\
\text { Stillbirth rate } \\
\text { Early neonatal } \\
\text { mortality }\end{array}$} & & . & 1.01 & 1.02 & 1.01 & 0.98 & 0.98 & 0.95 & 0.90 \\
\hline & & . & 0.98 & 0.99 & 0.97 & 0.98 & 0.93 & 0.93 & 0.86 \\
\hline & & . & 1.05 & 1.05 & 1.06 & 0.97 & $1 \cdot 04$ & 0.97 & 0.95 \\
\hline
\end{tabular}

which contribute substantially to the early neonatal death rate, ${ }^{9}$ were no less likely to occur at weekends than on weekdays. If this is true nationally, weekend births, while fewer in number, would include proportionately more spontaneous preterm deliveries, and thus weekends would have inflated death rates and probably, in particular, a raised early neonatal death rate. The stillbirth rate was also higher at weekends, however and possibly a lower level of staffing was responsible for this.

To investigate these and other possibilities, further analyses are needed of the causes of stillbirths and early neonatal deaths on each day of the week to see whether causes that may be associated with lack of medical care are more common at weekends. Such analyses would be possible for the years included in this study, but it would be difficult to interpret the findings in the absence of data on birth weight, which is such an important factor in perinatal mortality. ${ }^{10}$ The OPCS started to record birth weight in 1976 but does not yet receive this information for every birth. To investigate these and other perinatal problems, it would be highly desirable if a data system containing details of births, including birth weight in particular, and of causes of perinatal death could be developed nationally.

These data could not have been produced without the work of Pat Thew, of the computer division, OPCS ; and I also thank Ron Shaw, of the same department, for producing these preliminary daily totals of births. Thanks are due to Eva Alberman, Professor J R T Colley, Iain Chalmers, Malcolm Britton, and Josephine Weatherall and other colleagues in the OPCS for advice and help, and to the Registrar General for permission to publish.

Appendix 1 may be obtained from: Miss Alison Macfarlane, National Perinatal Epidemiology Unit, Research Institute, Churchill Hospital, Oxford OX3 7LJ.

\section{Appendix 2}

The Hospital In-Patient Enquiry does not distinguish between planned caesarean sections-that is, those booked in advance-and unplanned caesarean sections, for which the decision to operate was taken when the patient was already in labour. As unplanned caesarean sections may include those after induced labour some double counting occurs. This may be seen from table IV, which also shows how the numbers were corrected to allow for deliveries outside NHS hospitals and were thus expressed as a percentage of all deliveries. ${ }^{4}$ Caesarean sections without induction accounted for $3.4 \%$ of all deliveries. This may be compared with results of a survey of a sample of 2169 births in $1975,{ }^{7}$ in which $2^{\circ}$ of the births were by planned caesarean section.

TABLE IV-Proportions of women having labour induced in 1975 according to type of delivery ${ }^{6}$

\begin{tabular}{|c|c|c|c|c|c|}
\hline \multicolumn{4}{|c|}{ Delivery } & $\begin{array}{c}\text { No (")...) of } \\
\text { deliveries in } \\
\text { sample }\end{array}$ & $\begin{array}{l}\text { Estimated "., of } \\
\text { deliveries in } \\
\text { population }\end{array}$ \\
\hline \multicolumn{6}{|c|}{ Not induced } \\
\hline Caesarean section & & . & . & $1998(3 \cdot 6)$ & 3.4 \\
\hline Other $\ldots \quad \ldots$ & . & . & & $32709(59 \cdot 3)$ & $56 \cdot 0$ \\
\hline \multicolumn{6}{|c|}{ Induced } \\
\hline Caesarean section & . & .. & .. & $1330(2.4)$ & $2 \cdot 3$ \\
\hline Other $\ldots \quad \ldots$ & . & .. & . & $19149(34 \cdot 7)$ & $32 \cdot 8$ \\
\hline \multirow{2}{*}{\multicolumn{3}{|c|}{$\begin{array}{l}\text { Total No of induced labours . } \\
\text { Total No of caesarean sections } \\
\text { Total No of deliveries in sample }\end{array}$}} & $\cdots$ & $20479(37 \cdot 1)$ & $\begin{array}{r}35 \cdot 0 \\
5 \cdot 7\end{array}$ \\
\hline & & & $\therefore$ & $\begin{array}{r}3328(6 \cdot 0) \\
55186(100 \cdot 0)\end{array}$ & $5 \cdot 7$ \\
\hline
\end{tabular}

Total No of deliveries in $1975=603666$; total No of deliveries in NHS hospitals = 570040 .

The estimation method illustrated in table IV may be criticised for its assumption that no caesarean sections or inductions are performed outside NHS hospitals. Induction of labour is occasionally used for home confinements. No estimate is available of the number of these deliveries for which it is used, but they are few. Induction is more common in deliveries to private than to NHS patients, ${ }^{7}$ and the same is probably true of caesarean section, but no estimates exist for its use in deliveries in non-NHS hospitals over 1970-6. These deliveries, 
however, accounted for less than $2 \%$ of the total births over this period. The Hospital In-Patient Enquiry does not cover private patients in NHS hospitals, and the induction and caesarean section rates derived from it have been applied to all deliveries whether NHS or private in these hospitals. While this should technically result in an underestimate, the proportion of private patients is probably too small for the bias to be detectable. Thus the percentages quoted are probably slight underestimates, but the data that would be needed for better estimates are not collected.

\section{References}

${ }^{1}$ St Leger, A S, Applied Statistics, 1976, 25, 280.

2 Martins, J M, Medical fournal of Australia, 1972, 1, 487.
3 Rindfuss, R R, and Ladinsky, J L, Medical Care, 1976, 14, 685.

${ }^{4}$ Chalmers, I, and Richards, M, in Benefits and Hazards of the New Obstetrics, ed $\mathrm{T}$ Chard and $M$ Richards (Clinics in Developmental Medicine No 64). London, Spastics International Medical Publications, Heinemann, 1977.

5 Office of Population Censuses and Surveys, unpublished data.

6 Office of Population Censuses and Surveys, DHSS, and the Welsh Office, Hospital In-Patient Enquiry, 1966, 1974-5, Maternity Tables. To be published.

7 Cartwright, A, British Medical fournal, 1977, 2, 745.

${ }^{8}$ Stanley, F J, and Alberman, E D, Developmental Medicine and Child Neurology, 1978, 20, 300.

${ }^{9}$ Rush, R W, et al, British Medical fournal, 1976, 2, 965.

10 Brimblecombe, F S W, Ashford, J R A, and Fryer, J G, British fournal of Preventive and Social Medicine, 1968, 22, 27.

\title{
Treatment and survival in advanced breast cancer
}

\author{
T PRIESTMAN, M BAUM, VERA JONES, J FORBES
}

British Medical fournal, 1978, 2, 1673-1674

\section{Summary and conclusions}

The final results of a clinical trial comparing endocrine with cytotoxic drug treatment for advanced breast cancer were analysed. Although cytotoxic treatment gave a significantly higher response rate with a remission duration comparable to that obtained with endocrine treatment, the sequence in which the two treatments were given did not appear to influence survival-except possibly in women with rapidly progressing disease, when cytotoxic treatment is preferred.

\section{Introduction}

In a previous paper we gave the initial results of a prospective, randomised study comparing endocrine with cytotoxic drug treatment in women with advanced breast carcinoma. ${ }^{1}$ We now report the durations of remission, subsequent treatment, and survival of these women.

\section{Patients and methods}

One hundred women with locally recurrent or metastatic adenocarcinoma of the breast were allocated at random to receive either endocrine treatment or combination cytotoxic chemotherapy. Table I summarises the treatment regimens used; the rationale for their choice has been discussed. ${ }^{1}$ The criteria used for objective response were those recommended by the UICC. ${ }^{2}$ Entry to the study ended in December 1976. Most patients who failed to respond to or relapsed

Cardiff Breast Clinic, Velindre Hospital, Cardiff CF4 7XL

T PRIESTMAN, MRCP, FRCR, consultant in radiotherapy and oncology (present address: Wellcome Research Laboratories, Beckenham, Kent)

VERA JONES, MB, BS, medical assistant

Surgical Unit, University Hospital of Wales, Cardiff

M BAUM, MCHIR, FRCS, reader in surgery (present address: King's College Hospital, London SE5 9RS)

J FORBES, MS, FRCS, Nuffield fellow in surgery (present address: Royal Melbourne Hospital, Melbourne, Australia) on initial treatment were given further treatment. This treatment was not specified in the original protocol and so varied considerably. Several patients who received cytotoxic drugs initially were subsequently given endocrine treatment and vice versa.

\section{Results}

Of the 92 patients available for assessment, 47 were in the endocrine treatment group and 45 in the cytotoxic treatment group. Cytotoxic treatment produced significantly more responses than endocrine treatment $\left(P<0.02 ; \chi^{2}\right.$ test with Yates's correction for small numbers). There were six complete and four partial responses in the endocrine treatment group, and 11 complete and 11 partial responses in the cytotoxic treatment group. The median duration of response was 49 weeks (range 24-114) in the endocrine-treated patients and 47 weeks (range 12-100) in patients given cytotoxic agents. In both groups the median durations of remission in complete responders (endocrine group 56 weeks, cytotoxic group 50 weeks) were longer than in partial responders (endocrine group 42 weeks, cytotoxic group 40 weeks), but the differences were not significant. In the cytotoxic group three patients were still in remission at 78,92 , and 98 weeks respectively,

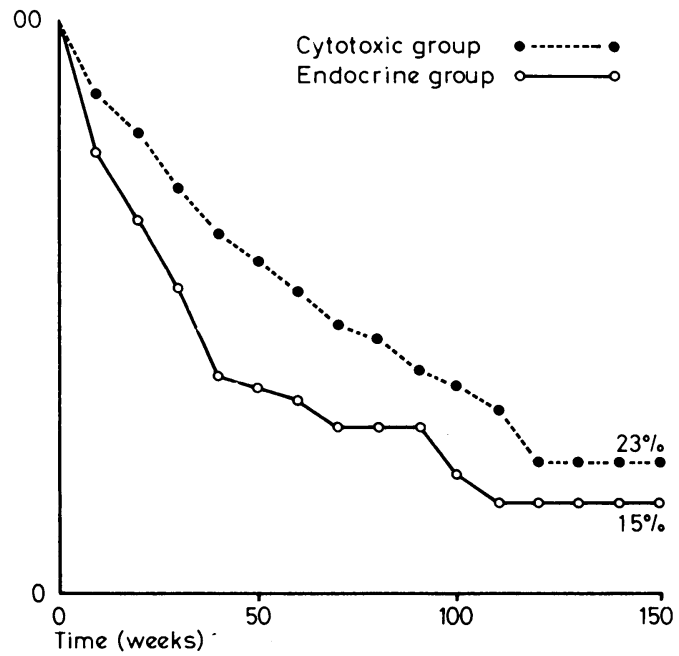

FIG 1-Overall survival in cytotoxic- and endocrine-treated patients (life table analysis by Peto log rank test). 